\title{
NATUREZA, PAISAGEM E AFETO EM POST TENEBRAS LUX DE CARLOS REYGADAS ${ }^{1}$
}

\author{
NATURE, LANDSCAPE AND AFFECT IN CARLOS REYGADAS'S \\ POST TENEBRAS LUX \\ NATURALEZA, PAISAJE Y AFECTO EN POST TENEBRAS LUX DE \\ CARLOS REYGADAS
}

Mariana Cunha

Resumo: este artigo examina a relação entre natureza e afeto no filme Post Tenebras Lux (Carlos Reygadas, 2012). Trata-se de compreender os efeitos da construção de paisagens fílmicas e afetivas, a partir de uma análise das formas de enquadramento de espaços naturais e figuras humanas e não humanas. A análise sugere que, ao intercalar uma série de cenas independentes da narrativa principal, os espaços tornam-se desconexos e autônomos, desorganizando a continuidade narrativa e enfatizando o quadro como o lugar da materialização dos afetos. Dessa forma, propõe-se que o espaço cinematográfico e as estratégias de enquadramento enfatizam a materialidade do cinema e do mundo e fazem uma conexão entre natureza, humanos e animais, evocando múltiplas subjetividades e criando um filme preocupado com o caráter imanente do cinema.

Palavras-chave: Natureza. Afeto. Carlos Reygadas.

Abstract: this article examines the relationship between nature and affect in Post Tenebras Lux (Carlos Reygadas, 2012). It aims to understand the effects of the construction of cinematographic and affective landscapes from the analysis of the framing strategies used to depict natural spaces and human and non-human bodies. The analysis

\footnotetext{
Uma versão inicial deste artigo foi apresentada no XXI Encontro da Sociedade Brasileira de Estudos de Cinema e Audiovisual (SOCINE), em João Pessoa, em outubro de 2017, no âmbito da pesquisa realizada com apoio do Programa Nacional de Pós-doutorado da CAPES.

2 Doutora em Cinema pelo Birkbeck College, University of London. Pós-doutoranda (PNPD/CAPES) no Programa de Pós-graduação em Comunicação da UFPE, Recife, PE, Brasil. http://orcid.org/0000-0003-12021194. E-mail: maccunha@gmail.com
} 
suggests that the interspersing of a series of sequences that are independent from the main narrative, the spaces become disconnected and autonomous, and disorganize narrative continuity while emphasizing the frame as the place for the materialization of affect. Hence, the article contends that the filmic space and the framing strategies emphasize the materiality of cinema and of the world, and connect nature, humans and animals, evoking multiple subjectivities, while also revealing the film's concern with the immanent character of cinema.

Keywords: Nature. Affect. Carlos Reygadas.

Resumen: este artículo examina la relación entre naturaleza y afecto en la película Post Tenebras Lux (Carlos Reygadas, 2012). Se trata de comprender los efectos de la construcción de paisajes fílmicos y afectivos, a partir de un análisis de las formas de encuadramiento de espacios naturales y figuras humanas y no humanas. El análisis sugiere que, al intercalar una serie de escenas independientes de la narrativa principal, los espacios se vuelven inconexos y autónomos, desorganizando la continuidad lógica de la narrativa, y enfatizando el cuadro como el lugar de la materialización de los afectos. De esta forma, se propone que espacio cinematográfico y las estrategias de encuadramiento enfatizan la materialidad del cine y del mundo y hacen una conexión entre naturaleza, humanos y animales, evocando múltiples subjetividades y revelando así una película preocupada por el carácter inmanente del cine.

Palabras clave: Naturaleza. Afecto. Carlos Reygadas.

\section{Introdução}

Os primeiros planos de Luz silenciosa (Carlos Reygadas, 2007) ${ }^{3}$ registram o nascer do sol em uma longa sequência de aproximadamente cinco minutos. A escuridão que ocupa a tela esvaece pouco a pouco; inicialmente, com o cintilar das estrelas e depois com os primeiros raios de sol que clareiam o horizonte. Nessa sequência, a câmera muda gradualmente o foco do céu para o horizonte, à medida que se aproxima da luz com um zoom, em um movimento que expõe uma paisagem rural ao amanhecer e convida o público a uma contemplação quase transcendental do espaço. Como P. Adams Sitney (1993) já observou, paisagens sublimes estão presentes no cinema desde o surgimento das primeiras técnicas da imagem em movimento, mas povoaram as imagens, sobretudo nos experimentos dos cinemas de vanguarda. $O$ olhar sobre as paisagens e fenômenos naturais e meteorológicos revela que "a natureza temporal da imagem aponta para o controle humano de

3 Do original: Stellet Licht. 
sua representação"4 (SITNEY 1993, p. 106, tradução nossa), como também para a capacidade que o cinema tem de registrar a temporalidade, o ritmo e o movimento desses fenômenos naturais. Do mesmo modo, a apreensão de aspectos sublimes mais sutis do espaço, como "o movimento das nuvens, mudanças na intensidade da luz, a sugestão de brisas na vibração e no balançar da flora e as gradações da chuva" permitiu ao cinema adentrar no que era "previamente o domínio exclusivo da poesia"5 (SITNEY, 1993, p. 113, tradução nossa).

Traçar a ideia de natureza no cinema aponta, em grande medida, para uma associação da representação do espaço natural com a experiência do sublime, com os limites da representação e a capacidade de compreender e controlar certos fenômenos, e, portanto, com um sentido de transcendência do humano. Nessa perspectiva, Jeffrey Pence sugere que "a abertura do sujeito frente ao sublime permite que surja uma afinidade com o infinito"6 (PENCE, 2004, p. 58, tradução nossa). O infinito, o inefável, o transcendental são elementos constitutivos de um certo "cinema espiritual"7, a exemplo de Tarkovsky e Bresson, com os quais, como afirma Tiago de Luca, o diretor mexicano Carlos Reygadas é comumente comparado (DE LUCA, 2010). Contudo, De Luca questiona a transcendência nos filmes de Reygadas, afirmando que seus filmes apresentam um excesso de materialidade ligado a uma ideia de carnalidade, recusando, assim, a relação direta entre a materialidade e a dimensão espiritual de seus filmes ${ }^{8}$. Apesar disso, a princípio, a sequência de abertura de Luz silenciosa remete a uma noção clássica de paisagem, que exige um certo distanciamento do olhar. No cinema, esse recorte do espaço natural é aliado a uma temporalidade prolongada e é produzido por uma subjetividade posta num lugar que separa o objeto do sujeito.

Essa noção de paisagem foi proposta por Anne Cauquelin que estudou o conceito na história da arte a partir de uma comparação com a noção de cenário. Em L'Invention du paysage, ela afirma que é "a ideia de paisagem, sua construção, que dá uma forma, um enquadramento, medidas a nossa percepção - distância, orientação, pontos de vista, situação, escala"9 (CAUQUELIN, 2007, p. 4, tradução

\footnotetext{
4 Do original: the temporal nature of the image points to the human control of its representation.

5 Do original: the movement of the clouds, changes in the intensity of light, the indication of breezes in the vibration and swaying of flora, and the gradation of rain" [...] "previously the exclusive domain of poetry.

6 Do original: the openness of the subject in the face of the sublime permits an affinity with the infinite to emerge. 7 Ver Schrader (1972) para estudo do estilo transcendental de alguns diretores.

8 O artigo de Tiago de Luca se concentra nos três primeiros filmes de Reygadas: Japón (Japão, 2003), Batalla en el cielo (Batalha no céu, 2005) e Stellet Licht (Luz silenciosa, 2007).

9 Do original: l'idée du paysage, sa construction qui donne une forme, un cadre, des mesures à nos perceptions - distance, orientation, points de vue, situation, échelle.
} 
nossa). Cauquelin defende que a paisagem na arte surge com uma mudança na importância dada ao espaço natural durante o Renascimento. Para o geógrafo Denis Cosgrove (1998), o olhar tem um papel fundamental na construção da paisagem, pois é a partir de um distanciamento do olhar que separa o sujeito do objeto que o mundo natural se transforma em uma paisagem. Desenvolvida e uma perspectiva marxista, a noção de Cosgrove remete ao nascimento da ideia de paisagem durante a passagem do Feudalismo para o Capitalismo, em que a ideia de propriedade e controle do espaço acarretou mudanças profundas na forma de observar e compreender o espaço (COSGROVE, 1998).

Há um deslocamento visível entre essa construção espacial da paisagem em Luz silenciosa e a forma como a sequência de abertura de Post Tenebras Lux (Reygadas, 2012) é construída. O quarto filme de Reygadas, lançado após cinco anos do lançamento do anterior, inicia com a sequência de um pôr do sol. Contudo, em vez de uma captura distanciada do espaço natural sem a presença de personagens, o início de Post Tenebras Lux é marcado por uma proximidade entre a câmera, os humanos e os animais. A câmera é colocada na altura de uma criança em um plano que enquadra seu rosto em close-up, enquanto ela corre atrás de cachorros e vacas em um pasto aberto. Nessa sequência, a criança, os animais e a natureza estão postos no filme sem um gancho narrativo claro. Durante os sete minutos da cena, o espaço deixa de ser apenas um pano de fundo e se impõe na imagem não só a partir da mudança temporal do anoitecer que se percebe gradativamente, mas principalmente pela forma como a câmera coreografa seu movimento e entrelaça-se à criança, aos animais e ao espaço, passando por rostos e corpos, revelando múltiplas subjetividades.

O cinema hegemônico também se utiliza, eventualmente, de procedimentos semelhantes. Basta lembrar aqui de E.T. - O Extraterrestre (E.T. the Extra-Terrestrial, Stephen Spielberg, 1982), uma das maiores rendas do cinema americano. Em uma das sequências em que o personagem do alienígena está sendo perseguido, a câmera também é colocada na altura do olhar de uma criança, focalizando a cintura dos perseguidores em meio aos flashes das lanternas. No caso do filme de Spielberg, tal artifício visa ampliar a tensão da perseguição, gerando a identificação do espectador com os perseguidos. Longe, portanto, de uma expansão das subjetividades, o que se procura em E.T. é a unificação do sentimento de tensão.

Em Post Tenebras Lux, a duração dos planos acompanha o cair da noite até que a tela se torna completamente escura, clareando apenas com a luminosidade intermitente de trovões. Já de início se percebe que a ideia de natureza que atravessa o filme distancia-se do sublime, mas constitui-se, como define Adrian 
Ivakhiv (2013), como "agente ativo e até mesmo sensível, que nos precede e em certo sentido nos faz surgir, mas também um que nos segue e nos cobre, assim como a terra cobre a terra na sua sedimentação de memórias, significados e ciclos elementais"10 (2013, p. 21, tradução nossa).

Este artigo se debruça sobre Post Tenebras Lux a partir de um pensamento ecológico, no sentido empregado por Anat Pick e Guinevere Narraway, ou seja, um pensamento fundamentado na materialidade do mundo e do cinema: "No lugar de noções clássicas de indicialidade [...] estamos lidando com a materialidade, que ambas as imagens fotográficas e digitais compartilham"11 (2003, p. 3, tradução nossa). Nesse sentido, as autoras destacam a continuidade entre o cinema e o mundo físico do qual ele faz parte e representa, ao afirmar que numa perspectiva ecológica, as materialidades do cinema abarcam a forma como este "registra, grava ou revela a realidade material de seus objetos; o lugar da imagem em movimento, fotográfica ou digital, na representação audiovisual; a relação entre o cinema e (...) os 'sujeitos-de-uma-vida'”'12, entre outras relações (2003, p. 2, tradução nossa). Essa perspectiva é alicerçada por estudos que têm colocado o meio ambiente e a natureza no centro de seus debates e que tem gerado, assim, uma renovação de perspectivas teóricas e novas áreas de investigação, entre elas a ecocrítica, a ecoestética e os estudos críticos animais. Essas áreas têm problematizado questões a partir das noções de antropoceno, não humano e pós-humano, ecojustiça, crise ambiental, entre outros. De forma semelhante, teóricos que defendem a virada do não humano como novo paradigma nas ciências humanas afirmam que a descentralização do humano abre possibilidades para pensar uma agência do não humano ao voltar sua atenção para "os animais, a afetividade, os corpos, sistemas orgânicos e geográficos, materialidades ou tecnologias"13 (GRUSIN, 2015, p. vii, tradução nossa). Na mesma linha, Stacy Alaimo afirma que:

Embora teorias de construção social tenham cumprido um trabalho inestimável por meio da crítica a categorias naturalizadas e opressoras de raça, classe, gênero, sexualidade e habilidade, do ponto de

\footnotetext{
10 Do original: active and even sentient agent, one that precedes us and that in some sense gives rise to us, but also one that follows us and covers us over, as earth covers earth in its sedimentation of memories, meanings, and elemental cycles.

1 Do original: instead of classical notions of indexicality, then, we are dealing with materiality, which both photographic and digital images share.

12 Do original: registers, records or reveals the material reality of its objects; the place of moving images, photographic or digital, in the audiovisual representation of the world; the relationship between film and (...) 'subject-of-a-life'.

13 Do original: animals, affectivity, bodies, organic and geophysical systems, materiality or technologies.
} 
vista ambiental, essas teorias podem colocar de lado ou minimizar a importância, substância e poder do mundo material ${ }^{14}$ (2010, p. 8, tradução nossa).

Essas perspectivas coincidem na atenção dada ao mundo material e aos novos materialismos que têm sido colocados em evidência através da crítica ao antropocentrismo ${ }^{15}$. Post Tenebras Lux compele o espectador a sentir e pensar o lugar da natureza como um elemento que desafia ideias tradicionais de espaço e representação. Considerando, na linha de Pick e Narraway (2003), que a natureza é uma "abertura para uma miríade de preocupações que tem a ver com o cotidiano, a história, a política e o formal”16 (p. 4-5), o artigo discute o papel das imagens da natureza na construção de paisagens fílmicas e afetivas, a partir de uma análise das formas de enquadramento de espaços naturais e figuras humanas e não humanas. Assim, a apreensão mais corpórea, afetiva e material do espaço natural pelas imagens do filme revela uma poética e uma ética da natureza representada.

Conhecidos por explorar questões emocionais através de uma série de recursos formais característicos, os filmes de Reygadas privilegiam a duração prolongada dos planos-sequência, a atenção excessiva à mise-en-scène e a obsessão pela materialidade, aspectos presentes em Japón (2002), Batalha no céu (2005) e Luz silenciosa (2007). Segundo Tiago de Luca, os filmes se voltam para temas recorrentes como religião, fé e espiritualidade, refletidos na forma contemplativa das imagens. A união desses temas a imagens da natureza sublime estaria de acordo com a afirmação de que a materialidade física dos filmes revelaria sua "dimensão metafísica" (DE LUCA, 2016, p. 39). No entanto, a relação da narrativa com as estratégias formais de construção do espaço fílmico como elemento que descentraliza o humano, colocando natureza, animais e humanos como agentes, cria um cinema de caráter imanente. Em outras palavras, Post Tenebras Lux põe em cena uma comunhão e uma presença imanente dos corpos, rostos, objetos e ambientes, em que não há um desequilíbrio radical nas relações de poder entre esses elementos no filme, mas uma coexistência baseada na coevolução e colaboração no mundo material.

\footnotetext{
14 Do original: Notwithstanding the fact that theories of social construction have performed invaluable cultural work by critiquing the naturalized and oppressive categories of race, class, gender, sexuality, and ability, from an environmentalist perspective, such theories may bracket or minimize the significance, substance, and power of the material world.

15 Ver Coole e Frost (2010).

16 Do original: an opening onto a myriad of concerns that have to do with everyday life, history, the political and the formal.
} 


\section{Afeto}

O filme retrata uma série de eventos e momentos comuns na vida de uma família de classe média alta, o casal Juan e Natália e seus dois filhos pequenos, Rut e Eleazar, paralelamente a outros eventos desconexos. A narrativa principal gira em torno de Juan, um homem de temperamento violento e viciado em pornografia, que flagra um assalto a sua casa cometido por Siete, um trabalhador que ocasionalmente presta serviços gerais a Juan. Nesse assalto, Siete atira em Juan e o filme acompanha a degradação de seu estado de saúde até sua morte. Filmado em torno da casa da família cercada de florestas, a construção espacial do filme se volta para os espaços naturais e para o mundo fenomenológico e sensorial, que espelha a ruína do casamento dos protagonistas, a decadência da saúde e a lenta morte de Juan, e o remorso de Siete.

O enredo é intercalado por uma série de sequências desconexas que desorganizam a linearidade temporal e a continuidade narrativa do filme. Várias delas apresentam personagens que não fazem parte da trama principal. Outras poderiam, a princípio, apontar para temas oníricos ${ }^{17}$, a exemplo de duas sequências inseridas no início e no final do filme, que retratam um lúcifer vermelho incandescente entrando silenciosamente numa casa à noite e dirigindo-se aos quartos onde dormem um casal e uma criança. Apesar da dimensão religiosa dessas duas cenas, não há relação direta de causa e efeito entre as sequências. Para além dessa interpretação, essas sequências autônomas manifestam duas tendências do filme: por um lado uma desdramatização da ação em relação ao enredo principal e uma dilatação temporal; por outro, uma preocupação com o corpo e o sensório.

Essa última é evidenciada especialmente na cena em que o casal se encontra no que parece ser uma sauna com diferentes ambientes onde vários corpos nus se olham e se oferecem sexualmente uns para os outros. A proximidade e a fragmentação dos corpos nus indicam o aspecto corpóreo e a fisicalidade das imagens ${ }^{18}$. De forma semelhante, há duas cenas que retratam um treino de rúgbi. Nelas, a câmera se mistura aos corpos que colidem e se movimentam bruscamente, mostrando também uma preocupação com um tipo de visualidade

\footnotetext{
17 Essa sugestão do universo onírico é evocada por uma das últimas cenas em que Juan, em seu leito de morte, pede para Natália tocar uma música no piano. Numa longa e sensível sequência, Natália canta It's a Dream de Neil Young.

18 Nota-se, aqui, uma estratégia que se diferencia, por exemplo, da exposição de corpos nus dos filmes pornográficos. Ao invés de focalizar a ato sexual em si, os planos em Post Tenebras Lux enquadram numerosos e distintos corpos, muitas vezes aproximando a câmera às superfícies que tornam esses corpos imagens quase abstratas. Este tipo de enquadramento imprime outro tipo de corporeidade e exploração sensória.
} 
háptica, como teorizado por Laura Marks (2000). A ênfase na tatilidade denota um "engajamento com a materialidade do mundo"19, como afirma Jennifer Barker (2009, p. 2, tradução nossa). Para ela, o tátil é uma forma de estar no mundo e o cinema, "uma experiência íntima"2o (BARKER, 2009, p. 2, tradução nossa). Nesse sentido, é possível afirmar que essa ênfase no corpo e no háptico também contribui para o desequilíbrio da linearidade narrativa, cujos espaços perdem suas especificidades geográficas e espaciais, e sua ancoragem em um lugar.

Essa indeterminação espacial nos remete ao conceito de Deleuze de "espaço qualquer", caracterizado - dentro do contexto do pós-guerra a que se refere o filósofo - como espaços desconectados ou esvaziados, que adquirem certa autonomia estética e em que "os personagens se encontravam cada vez menos em situações sensório-motoras 'motivadoras' e cada vez mais num estado de passeio, de perambulação ou de errância que definia situações óticas e sonoras puras" ${ }^{\prime 21}$ (DELEUZE, 1986, p. 120, tradução nossa). Os espaços quaisquer "constituem imagens que despertam uma resposta emocional e visceral"22 (MARKS, 2000, p. 28, tradução nossa), ou, como sugere Deleuze, são lugares onde se desenvolvem "os afetos modernos de medo, de desapego, mas também de frescor, de velocidade extrema e de espera interminável"²3 (DELEUZE, 1986, p. 121, tradução nossa).

Para Brian Massumi, o afeto faz parte de uma "lógica da intensidade"24 (MASSUMI, 1996, citado por RUTHERFORD, 2013, p. 94), diferente da emoção que é semanticamente dependente de um conteúdo motivador. Massumi argumenta que emoção e afeto fazem parte de duas dimensões distintas, porém dialogam entre si, ou seja, uma não exclui a outra. Assim, "o afeto não era reduzido a significados linguísticos, simbólicos ou conceituais, mas operava como uma intensidade que se move em corpos humanos e não-humanos"25 (GRUSIN, 2015, p. xvii). Ainda segundo Grusin, "sistemas afetivos funcionam autonomamente e automaticamente, independentes de (e, de acordo com Massumi, anteriormente à) cognição, emoção, vontade, desejo, propósito, intenção ou crença - todos atributos do tradicional sujeito humanista

\footnotetext{
19 Do original: engagement with the materiality of the world.

20 Do original: an intimate experience.

21 Do original: the characters were found less and less in sensory-motor 'motivating' situations, but rather in a state of strolling, of sauntering or of rambling which defined pure optical and sound situations".

22 Do original: constitute images that arouse an emotional and visceral response.

23 Do original: the modern affects of fear, detachment, but also freshness, extreme speed and interminable waiting.

24 Do original: logic of intensity.

25 Do original: affect was not reducible to linguistic, symbolic or conceptual meanings but operated as an intensity moving through human and nonhuman bodies alike.
} 
liberal"26 (2015, p. xvii). Nesse sentido, o afeto excede a representação simbólica e estaria ancorado no corpo e nos sentidos. Como Jill Bennett (2005) sugere, "o afeto na arte não opera no sentido de despertar compaixão por personagens pré-definidos; ele tem uma força própria. [...] Vai além do reforçar emoções morais que definem reações a cenários narrativos específicos" ${ }^{27}$ (BENNETT, 2005, citada por RUTHERFORD, 2013, p. 91).

Conceito chave da imagem-movimento de Deleuze, a imagem-afecção deriva da noção bergsoniana de afecção, que para Roberto Machado, era definida como "uma tendência motora sobre um nervo sensível, ou uma série de micromovimentos sobre uma placa nervosa imobilizada" (MACHADO, 2009, p. 262). As afecções seriam, portanto, "os estados dos corpos provenientes da ação de outros corpos sobre eles"; já "os afetos são as variações contínuas desses estados em termos de aumento e diminuição da potência de ser e agir" (MACHADO, 2009, p. 262). Fatorelli (2012, p. 49) explica que,

a afecção mede [o] poder absorvente, aponta para o interior do corpo, para o que esse corpo acrescenta aos corpos exteriores. Portanto, mais do que prolongar estímulos externos em ações consecutivas, além de reagir de modo previsível em concordância com o hábito e com as demandas imediatas, o centro de indeterminação pode produzir uma experiência singular, criar novos hábitos, despertar novas disposições.

A imagem-afecção estaria, assim, entre a percepção e a ação, fora dos domínios da linguagem. Na teoria deleuziana, há uma paridade entre a imagem-afecção, o close-up e o rosto, pois revelam uma qualidade pura e uma ligação corpórea entre a imagem e o espaço (BOGUE, 2003). Em Post Tenebras Lux, alguns aspectos reforçam a relação entre $o$ afeto como intensidade e a corporeidade, e apontam para uma dimensão ética da conexão entre imagem, natureza e afeto. Algumas sequências indicam essa conexão, a exemplo da cena inicial do filme analisada previamente. Em uma perspectiva ecológica, a dimensão ética da representação da natureza e da realidade física, segundo Ivakhiv, faz parte de um campo que "defende que mais atenção seja dada à relação entre o mundo produzido pelo

26 Do original: Affect systems operate autonomously and automatically, independent of (and according to Massumi, prior to) cognition, emotion, will, desire, purpose, intention, or belief-all conventional attributes of the traditional liberal humanist subject.

27 Do original: affect in art does not operate at the level of arousing sympathy for predefined characters; it has a force of its own [...] it goes beyond reinforcing the moral emotions that shape responses to a particular narrative scenario. 
cinema e os mundos dos quais e dentro dos quais eles são produzidos - mundos que são materiais e biofísicos, assim como sociais e epistemológicos"28 (2013, p. 22 , tradução nossa). Não surpreende que o diretor tenha escolhido uma criança para protagonizar essa sequência inicial, justamente porque enfatiza uma afetividade que remete a uma ordem não linguística, uma experiência dos sentidos, assim como uma ênfase na materialidade que é compartilhada por humanos e não humanos. Post Tenebras Lux apresenta, já nos primeiros planos, uma possibilidade de pensar os afetos na experiência compartilhada entre humano e o não humano, e de atribuir uma "agência" ao não humano.

Percebe-se, além do espaço natural fortemente retratado, desde as primeiras imagens, o formato não convencional do filme: quase quadrado, simulando o formato agora obsoleto que se tornou padrão nos anos 1930 (1.37:1), a imagem aparece com as margens refratadas ou duplicadas, resultado do uso de uma lente acoplada à câmera. O formato indica uma preocupação com a forma de percepção da imagem, apontando para a própria materialidade do cinema e produzindo certo grau de opacidade. Com esse elemento, o espectador é constantemente lembrado do espaço do quadro, sua visão é ofuscada pela falta de transparência das margens da lente, evocando a natureza física do sentido da visão. Como coloca Malcolm Turvey, retomando formulações anteriormente elaboradas por Jean Esptein, o cinema desvela uma "relação perceptual entre o espectador e o mundo fenomenológico"29 (TURVEY, 1998, p. 35, tradução nossa), que é íntima e corpórea. Ou seja, longe de aderir a uma ideia de transparência, o filme traz uma ideia de visão corpórea, opaca, que permite um conhecimento sensorial do mundo fenomenológico, através da produção de uma textura que evoca a constante presença material da imagem.

\section{Natureza}

Em Post Tenebras Lux, a natureza é construída menos como lugar de contemplação ou paisagem do que como um agente senciente e vivo. Uma paisagem pura, de acordo com Silke Panse, "depende da separação do seu ambiente humano"30 (2013, p. 53, tradução nossa), tornando a paisagem uma vista e sua contem-

\footnotetext{
28 Do original: advocates for greater attention to be paid to the relationship between the world produced by cinema and the worlds from and within which they are produced - worlds that are material and biophysical as well as social and epistemological.

29 Do original: the perceptual relation between the spectator and the phenomenal world.

3o Do original: depends on the separation from its human environment.
} 
plação, um espetáculo, resultado de um distanciamento entre ser e espaço. No entanto, numa perspectiva ecoestética, "a imagem não pode ser separada de suas conexões materiais com o mundo"31 (PANSE, 2013, p. 54, tradução nossa). No nível narrativo, esse elemento é percebido em uma das cenas em que Siete, o lenhador que presta alguns serviços a Juan e no final do filme o assalta e mata, é contratado para cortar uma árvore. A sequência começa com um plano fixo que enquadra uma árvore no centro e ouvem-se sons de latidos e relinchar de cavalos. Após alguns momentos, ainda de longe, um homem aparece de trás da árvore. Ao chegar, Siete pergunta por que Guante quer cortar a árvore e ele responde que quer irritar a irmã, diz que ela pensa que as árvores conversam entre si, que estão vivas. A câmera oscila entre as perspectivas dos personagens, mas o enquadramento também sugere uma perspectiva a partir da árvore.

Não se trata, no entanto, de um movimento antropomórfico, mas da atribuição de uma agência ao não-humano. Seguindo um pensamento ecoestético, é possível entender as complexidades das relações entre seres, ambientes e objetos a partir de uma noção expandida de agência, ou seja, pensar além do entendimento tradicional de sujeito e objeto, e da "simples associação de 'vontade' e 'racionalidade' como os principais impulsionadores de ações terrenas" ${ }^{32}$ (DÜRBECK e SULLIVAN, 2015, p. 121, tradução nossa). Nessa perspectiva, intenção e intencionalidade humana não são os únicos elementos determinantes da agência. Para Dürbeck e Sullivan:

Agência, entendida de forma abrangente para incluir seres vivos assim como forças como radioatividade, energia solar, clima, gravidade e fluxos de matéria, é então uma força distribuída, emergente, que pode criar ordem e desordem com ou sem intencionalidade. Força de vontade existe, mas funciona como resposta a vários fatores, incluindo linguísticos, culturais, biológicos, químicos e ecológicos. Essa visão mais inclusiva é inerentemente ambiental na medida em que situa o ser humano dentro do domínio de atores múltiplos e insiste que somos participantes - ao invés de supervisores - na troca contínua que abrange a biosfera. Definir agência de forma ampla para incluir atividades humanas e animais assim como outros fatores não-humanos

31 Do original: the image cannot be separated from its material connections to the world.

32 Do original: simple association of 'will' or 'rationality' as primary drivers in earthly actions. 
não erradica a agência humana, mas a alinha a um contínuo que inclui a capacidade de agência da matéria ${ }^{33}$ (2015, p. 122, tradução nossa).

De certa forma, essa sequência indica uma desigualdade radical entre humanos e não-humanos, ou como afirmou John Berger sobre a relação entre humanos e animais, "sua falta de uma linguagem comum, seu silêncio [que] garante sua distância, sua distinção, sua exclusão"34 (BERGER, 1992, p. 6, tradução nossa). Enquanto o diálogo entre Siete e Guante demonstra essa desigualdade radical entre humanos e não humanos ao dar uma ideia de antropomorfização da natureza, a escolha dos planos sobre os elementos e figuras não humanas, com extensa duração, reforça a potencialidade da sua presença sensível. Post Tenebras Lux oscila entre uma ideia de presença compartilhada e a oposição radical entre seres, objetos e ambientes. Por um lado, as imagens da natureza evidenciam a proximidade e a imanência do mundo físico. Por outro, a oposição e a desigualdade entre humanos e não humanos são frequentemente sugeridas; a exemplo da cena que retrata uma família caçando aves com rifles intercalada e sem continuidade no enredo, e a cena em que Juan espanca seu cachorro, cuja intensidade representa a irracionalidade e o descontrole de Juan bem como um grau de animalidade na sua fúria.

Em momentos distintos, o filme apresenta a natureza como presença e materialidade. No início do filme, observamos Siete atravessar uma floresta, parando para cortar árvores. No entanto, ele parece apenas chanfrar as árvores e não as derruba. A sequência começa com uma imagem prolongada da neblina sobre a topografia montanhosa da floresta. A duração do plano é longa e reflete o movimento sutil da neblina sobre as árvores. Em seguida, Siete se aproxima, desce do cavalo, seus dois cães o seguem. A câmera panorâmica acompanha Siete, que liga a motosserra e se aproxima de uma árvore. Agora, o tronco da árvore está no centro do quadro; Siete atrás dela, quase completamente invisível. Tanto nessa, quanto na cena com Guante, os personagens surgem de trás de uma árvore. Outra panorâmica atravessa a floresta em meio a suas árvores, de forma

33 Do original: Agency, understood broadly to include living beings as well as such forces as radioactivity, solar energy, weather, gravity, and flows of matter, is thus a distributed, emergent force that can create order or disorder with or without intentionality. Willpower exists, but it functions in response to many factors including linguistic, cultural, biological, chemical, and ecological ones. This more encompassing view is inherently environmental in that it situates the human being within a realm of manifold actants, and insists that we are participants-instead of the overseers-in the ongoing exchanges that encompass the biosphere. Defining agency broadly to include human and animal activity as well as other nonhuman factors does not eradicate human agency, but rather aligns it on a continuum with matter's agentic capacity.

34 Do original: its lack of a common language, its silence, [which] guarantees its distance, its distinctness, its exclusion. 
que a proximidade da câmera às árvores dá a impressão de quase tocá-las. Os próximos planos mostram um close-up do rosto do cavalo, depois os cachorros, até que mais um plano em movimento retrata Siete partindo a cavalo.

O enquadramento da árvore esconde a ação, indicando uma inversão do campo e do extracampo. O som da motosserra é o que revela que, em algum lugar fora do nosso campo de visão, o corte de uma árvore está em curso. Notadamente, o filme traz à tona os elementos convencionalmente tidos como acessórios para o centro da imagem. Essas cenas são exemplos expressivos da estratégia utilizada por Reygadas, que remete à distinção entre os conceitos de ergon e parergon (noções que se referem, respectivamente, ao foco da obra de arte e ao conjunto de elementos acessórios à cena). O parergon estaria, assim, a serviço de algo, seria incidental, subordinado, secundário. Contudo, os limites entre ergon e parergon nem sempre são visíveis. Em um ensaio dedicado ao conceito de parergon, Derrida descreve uma escultura de mármore de um nu feminino envolto por tecidos drapeados, que funcionam como moldura, como para encobrir partes íntimas do corpo nu. "Onde começa o parergon, onde ele termina"35, questiona Derrida (1979, p. 22, tradução nossa). Para o filósofo, "o parergon inscreve algo extra, exterior ao campo específico (...), mas cuja exterioridade transcendente toca, brinca com, desliza, roça ou pressiona o limite e intervém no interior, uma vez que, no interior, algo está faltando. Faltando algo e faltando a si mesmo"36 (DERRIDA, 1979, p. 21, tradução nossa).

Martin Lefebvre (2006) retoma esses conceitos da história da arte para explicar o surgimento do gênero da paisagem na pintura, a partir de uma mudança no modo de ver o que antes era marginal - o espaço natural como cenário (parergon) para uma ação -, passando a vê-lo como o foco (ergon) da imagem. Essa transformação da representação - que privilegia o espaço natural em detrimento da ação - e do modo de ver do observador - que passa a enxergar o espaço como autônomo e significante em si mesmo - marca, segundo Lefebvre, o surgimento de paisagens autônomas. Em Post Tenebras Lux, há uma inversão radical: o cenário não apenas passa a ter uma importância própria, mas se dá a partir do encobrimento da ação dramática.

Esse é um recurso recorrente. Um exemplo é talvez a cena mais violenta do filme, em que Juan perde o controle e espanca um de seus cachorros. Aqui, a câmera

35 Do original: Where a parergon begins, and where it ends.

36 Do original: The parergon inscribes something extra, exterior to the specific field [...], but whose transcendent exteriority touches, plays with, brushes, rubs, or presses against the limit and intervenes internally only insofar as the inside is missing. Missing something and is itself missing. 
focaliza o rosto de Juan enfurecido, mas a ação fica fora de quadro. A violência, no entanto, é transmitida também pelo som dos latidos e do grito de Natália que obriga Juan a parar. O que se vê nessa cena, antes da ação dramática - a violência física do cão sendo maltratado pelo seu dono - é o conteúdo afetivo do rosto de Juan. A intensidade afetiva surge primeiro; já a compreensão é retrospectiva.

Outro elemento crucial percebido na cena do corte da árvore é a ênfase na textura da imagem. A imagem em si não "explica" o evento, ela esconde a ação. Porém, o foco está nos troncos das árvores: o espectador se depara com uma proximidade em relação ao espaço. Como Laura Marks sugere, "a inabilidade de reconhecer uma imagem nos leva a confrontar os limites do nosso conhecimento, enquanto a recusa do filme em estender-se em uma ação constitui uma recusa a 'explicar' e neutralizar a imagem virtual"37 (2000, p. 47, tradução nossa). Em Post Tenebras Lux, a ideia de proximidade com a superfície da imagem, com sua textura, remete novamente ao conceito de imagem háptica. Do ponto de vista da experiência fílmica, esse tipo de imagem ganha uma potência afetiva decorrente do contato visual com a sua superfície e textura. ${ }^{38}$ Imagens hápticas surgem a partir de um espaço de proximidade, que "privilegia a presença material da imagem"39 (MARKS, 2000, p. 163, tradução nossa). Nesse sentido, a materialidade de uma imagem se encontra nos "aspectos que escapam ao nosso reconhecimento simbólico"40 (MARKS, 2002, p. xi, tradução nossa). A autora relaciona a imagem háptica a um tipo específico de imagem-afecção, ou seja, uma imagem que "geralmente se estende em uma ação, [e que] também pode nos levar a uma contemplação visceral e emocional dos espaços quaisquer esvaziados de ação"141 (2000, p. 163, tradução nossa).

O filme intercala imagens hápticas e imagens óticas, enfatizando escalas extremas e estabelecendo um movimento constante entre distanciamento e proximidade, em que oscilam imagens abertas que privilegiam o espaço exterior

\footnotetext{
37 Do original: the inability to recognize an image encourages us to confront the limits of our knowledge, while the film's refusal to extend into action constitutes a refusal to 'explain' and neutralize the virtual image. ${ }_{38}$ Giuliana Bruno compara a superfície do rosto com a de uma paisagem, afirmando que o afeto pode surgir a partir de imagens de paisagens que revelam sua tatilidade (Bruno, 2014). A autora propõe que "o 'espaço-qualquer' pode se tornar o elemento genético da 'imagem-afecção' na medida em que envolve um sentido de espaço tangível: um sentir material de texturas que pode se tornar visível na superfície" (BRUNO, 2014, p. 15). (Do original: "any-space-whatever" can become the genetic element of the "affection-image" insofar as it involves a tangible sense of space: a material sensing of textures that can become visible on the surface").

39 Do original: privileges the material presence of the image.

40 Do original: "spects that escape our symbolic recognition.

${ }_{41}$ Do original: usually extends into action, [and that] may also force a visceral and emotional contemplation in those any-spaces-whatever divorced from action.
} 
e imagens do pequeno detalhe. O uso deste recurso é evidenciado em uma das últimas cenas do filme, que retrata o suicídio de Siete após receber a notícia da morte de Juan. Enquanto caminha até um vale, a câmera, em uma sequência em tracking, acompanha o personagem, em uma série de planos muito próximos ao seu corpo. Primeiro, focaliza sua mão enquanto Siete caminha. Depois, segue um close-up extremo de sua orelha, depois outro de sua outra mão. Após isso, a câmera, de frente para Siete, fragmenta seu corpo, mostrando apenas seu quadril e suas mãos. Siete, então, para de caminhar. Em seguida, surge a paisagem de um pinhal, em um plano aberto, que se estende até o horizonte. Lentamente, acompanhada do som de um tronco envergando, uma das árvores cai. Na sequência, há um plano no meio das árvores, que mostra os pinheiros em queda, um após o outro.

O ímpeto dessa cena não se encontra apenas na grandiosidade da paisagem ou nos efeitos criados pelo jogo dos planos que oscilam entre proximidade e distanciamento. Para além disso, o espectador é posto diante da conexão inerente entre humanos e não humanos. A natureza deixa de ser uma paisagem distanciada - que sugere um abismo entre o observador e a imagem - para se transformar em um elemento determinante da experiência sensível do mundo. No final da cena, Siete aparece de costas, mirando a montanha e, depois de alguns momentos, arrancando a própria cabeça do corpo, que cai morto no chão. Essa cena termina com uma chuva avermelhada e planos de vacas pastando, o que indica, novamente, a dimensão sensível da natureza, assim como sua agência, seu arbítrio (IVAKHIV, 2013). É visível o foco dado ao espaço natural e ao animal, que traz uma consciência da materialidade compartilhada e a presença do elemento não-humano.

\section{Considerações finais}

Post Tenebras Lux narra uma série de eventos do cotidiano de uma família de classe média e elege a casa onde vivem e o seu entorno como o cenário principal do filme. No entanto, a narrativa é intercalada por diversas cenas que desorganizam a linearidade temporal do filme. Além daquelas comentadas anteriormente, outras são sugestivas de uma atenção a questões sociais, como, por exemplo, duas sequências em que a presença da família branca e de classe média de Juan em locais frequentados por grupos sociais menos favorecidos gera um atrito.

Por outro lado, a escolha dos lugares e a construção espacial do filme enfatizam os espaços naturais, assim como o mundo sensiorial e fenomenológico, que refletem o drama vivido pelos personagens. Entre as estratégias utilizadas, 
o filme ressalta o enquadramento desses espaços e o quadro como lugar do surgimento do afeto enquanto intensidade. Há uma construção do espaço como elemento que conecta natureza, paisagens, objetos, animais e humanos, revelando múltiplas subjetividades e criando um cinema de caráter imanente.

Esse aspecto determinante do filme reverbera a ideia de "face do mundo" de Merleau-Ponty, para quem, na leitura de Glen Mazis (2016), a face do mundo e a face das coisas têm uma "dimensão específica de significado que fala da habilidade que nossa percepção tem de situar uma existência corpórea dentro da matriz de sentidos do mundo"42 (MAZIS, 2016, p. 75, tradução nossa). A face do mundo teria então um sentido fisionômico que pode ser apreendido não discursivamente, 0 que ecoa as ideias de Laura Marks (2000) e Guiliana Bruno (2014) sobre a textura, o afeto e a dimensão corpórea do cinema. No filme de Reygadas, percebe-se uma proximidade e uma ênfase na relação entre os personagens e seu entorno que não se reduz a uma visão antropocêntrica do mundo, mas aponta para uma consciência dos limites do humano e da continuidade entre humanos, animais e natureza. Isso se dá a partir de algumas estratégias estéticas que articulam essa visão: a falta de linearidade espacial e temporal da narrativa, a opacidade, a duração estendida dos planos dos espaços naturais e dos animais, a atenção ao extracampo, a preferência por uma visualidade háptica, especialmente no uso dos close-ups. Essas estratégias destacam a presença material dos espaços, seres e objetos, já que as situações não são necessariamente motivadas por ações e reações. Longe de ser excesso, a imagem sensorial e afetiva destaca o valor do papel dos sentidos na experiência social, política, histórica e geográfica do mundo. Talvez, o tema principal de Post Tenebras Lux seja a relação de seu personagem com suas maiores fantasias e traumas e é permeado por numerosos elementos que expõem os conflitos sociais do México contemporâneo. Contudo, o filme insiste nas imagens que refletem a relação entre os personagens e seu espaço, numa proximidade quase extrema com o mundo físico. A natureza se torna, portanto, um elemento determinante na criação de novas formas de imaginar a relação entre humanos e não-humanos e de conceber nosso lugar no mundo.

42 Do original: specific dimension of meaning that addresses perception's ability to situate embodying being within the matrix of sense of the surrounding world. 


\section{Referências}

ALAIMO, S. Bodily Natures: Science, Environment, and the Material Self. Bloomington: Indiana University Press, 2010.

BARKER, J. The Tactile Eye: Touch and the Cinematic Experience. Berkeley: University of California Press, 2009.

BATALLA en el cielo (Batalha no céu). Direção: Carlos Reygadas. Produção: Philippe Bober, Susanne Marian, Hamish McAlpine, Carlos Reygadas, Jaime Romandia, Joseph Rouschop. Intérpretes: Marcos Hernández, Anapola Mushkadiz, Bertha Ruiz, David Bornstein, Rosalinda Ramirez et al. México, Bélgica, França, Alemanha, Holanda: Coproduction Office. [S. I.]: No Dream Cinema, Mantarraya Producciones, Tarantula, 2005. (98 min), son., color., 35mm.

BERGER, J. Why Look at Animals. In: About Looking. Londres: Vintage, 1992.

BOGUE, R. Deleuze on Cinema. Londres: Routledge, 2003.

BRUNO, G. Surface: matters of aesthetics, materiality and media. Chicago: University of Chicago Press, 2014. https://doi.org/10.7208/chicago/9780226114835.001.0001

CAUQUELIN, A. L’invention du paysage. 3. ed. Paris: Quadrige/PUF, 2007.

COOLE, D.; FROST, S. (org.). New Materialisms: Ontology, Agency, and Politics. Durham: Duke University Press, 2010. https://doi.org/10.1215/9780822392996

COSGROVE, D. E. Social Formation and Symbolic Landscape. Madison: The University of Winsconsin Press, 1998.

DELEUZE, G. Cinema 1: The Movement-Image. Minneapolis: University of Minnesota Press, 1986.

DE LUCA, T. Carnal Spirituality: The Films of Carlos Reygadas. Senses of Cinema, n. 55, 2010. Disponível em: http://sensesofcinema.com/2010/feature-articles/carnal-spirituality-the-films-of-carlos-reygadas-2/ - b26. Acesso em: 15 jan. 2018.

DE LUCA, T. Natural Views: Animals, Contingency and Death in Carlos Reygadas's Japón and Lisandro Alonso's Los Muertos. In: DE LUCA, T.; JORGE, N. B. (orgs.). Slow Cinema. Edimburgo: Edinburg University Press, 2016. p. 219-230.

DERRIDA, J. The Parergon. October, n. 9, p. 3-41, 1979. https://doi.org/10.2307/778319

DURBECK, G.; SCHAUMANN. C.; SULLIVAN, H. Human and Non-human Agencies in the Anthropocene. Ecozone, v. 6, n. 1, p. 118-136, 2015.

E.T. - O Extraterrestre (E.T. the Extra-Terrestrial). Direção: Steven Spielberg. Produção: Kathleen Kennedy, Melissa Mathison, Steven Spielberg. Intérpretes: Henry Thomas, 
Drew Barrymore, Peter Coyote e outros. Estados Unidos: Universal Pictures, 1982. (115 $\mathrm{min})$, son., color., $35 \mathrm{~mm}$.

FATORELLI, A. Imagem e afecção. Revista Galáxia, n. 23, p. 48-58, 2012.

GRUSIN, R. (org.). The Non-Human Turn. Minneapolis: University of Minnesota Press, 2015 .

IVAKHIV, A. Ecologies of the Moving Image: Cinema, Affect, Nature. Waterloo: Wilfrid Laurier University Press, 2013.

JAPÓN (Japão). Direção: Carlos Reygadas. Produção: Carlos Reygadas, Jaime Romandia, Carlos Serrano Azcona, Gerardo Tagle. Intérpretes: Alejandro Ferretis, Magdalena Flores, Yolanda Villa, Martín Serrano e outros. México, Alemanha, Holanda, Espanha: No Dream Cinema, Mantarraya Producciones, Solaris Film, 2003. (130 min), son., color, $35 \mathrm{~mm}$ (blow-up).

LEFEBVRE, M. Between Setting and Landscape in the Cinema. In: LEFEBVRE, M. (org.). Landscape and Film. Nova York: Routledge, 2006. p. 19-59. https://doi. org/10.4324/9780203959404

STELLET Licht (Luz silenciosa). Direção: Carlos Reygadas. Produção: Jeroen Beker, Rémi Burah, Jean Labadie, Carlos Reygadas, Jaime Romandia, Frans van Gestel. Intérpretes: Cornelio Wall, Miriam Toews, Maria Pankratz, Peter Wall, Jacobo Klassen e outros. México, França, Holanda, Alemanha: Mantarraya Producciones, No Dream Cinema, Bac Films, 2007. (127 min), son., color., 35mm.

MACHADO, R. Deleuze, a arte e a filosofia. 2. ed. Rio de Janeiro: Zahar, 2009.

MARKS, L. U. The Skin of Film. Durham: Duke University Press, 2000.

MARKS, L. U. Touch: Sensuous Theory and Multisensory Media. Minneapolis: University of Minnesota Press, 2002.

MAZIS, G. Merleau-Ponty and the Face of the World: Silence, Ethics, Imagination and Poetic Ontology. New York: SUNY Press, 2016.

PANSE, S. Ten Skies, 13 Lakes, 15 Pools: Structure, Immanence and Eco-aesthetics in The Swimmer and James Bennings' Land Films. In: PICK, A.; NARRAWAY, G. (org.). Screening Nature: Cinema Beyond the Human. Nova York: Berghahn Books, 2013. p. 37-59.

PENCE, J. Cinema of the Sublime: Theorizing the Ineffable. Poetics Today, v. 25, n. 1, p. 29-66, 2004. https://doi.org/10.1215/03335372-25-1-29

PICK, A.; NARRAWAY, G. (org.). Screening Nature: Cinema Beyond the Human. Nova York: Berghahn Books, 2013. 
POST Tenebras Lux. Direção: Carlos Reygadas. Produção: Rémi Burah, Daniel Graham, Arnold Heslenfeld, Jean Labadie, Fiorella Moretti, Carlos Reygadas, Jaime Romandia, Frans van Gestel, Michael Weber. Intérpretes: Adolfo Jiménez Castro, Nathalia Acevedo, Rut Reygadas, Eleazar Reygadas, Willebaldo Torres e outros. México, França, Holanda, Alemanha: No Dream Cinema, Mantarraya Producciones, Le Pacte, Topkapi Films, 2012. (115 min), son., color., 35mm/DCP.

RUTHERFORD, A. Film, Trauma and the Enunciative Present. In: ATKINSON, M.; RICHARDSON, M. (org.). Traumatic Affect. Cambridge: Cambridge Scholars Publishing, 2013. p. 80-128.

SCHRADER, P. Transcendental Style in Film: Ozu, Bresson, Dreyer. Berkeley: University of California Press, 1972.

SITNEY, P. A. Landscape in the Cinema: The Rhythms of the World and the Camera. In: KEMAL, S.; GASKELL, I. Landscape, Natural Beauty and the Arts. Cambridge: Cambridge University Press, 1993. p. 103-126. https://doi.org/10.1017/CBO9780511554605.005

TURVEY, M. Jean Epstein's Cinema of Immanence: The Rehabilitation of the Corporeal Eye. October, n. 83, p. 25-50, 1998.

\section{Dados da autora:}

\section{Mariana Cunha - maccunha@gmail.com}

Pesquisadora de Pós-Doutorado PNPD/CAPES no Programa de Pós-Graduação em Comunicação da Universidade Federal de Pernambuco - UFPE. Doutora em Cinema e Mestra em Cultural and Critical Studies pelo Birkbeck, University of London.

Endereço da autora: Universidade Federal de Pernambuco, Centro de Artes e Comunicação, Programa de Pós-Graduação em Comunicação. Cidade Universitária, Av. Prof. Moraes Rego, s/n, 50.670-901 - Recife (PE) - Brasil 